\title{
O PROBLEMA SOCIAL COM A VIOLÊNCIA DE GÊNERO COM A MULHER: UM DESAFIO NA SOCIEDADE COM O ENFRENTAMENTO DESENFREADO POR QUESTÕES E CUIDADOS COM O DIREITO À VIDA
}

\author{
THE SOCIAL PROBLEM WITH GENDER-BASED VIOLENCE AGAINST WOMEN: A \\ CHALLENGE IN SOCIETY WITH UNRESTRAINED COPING WITH ISSUES AND \\ CARE FOR THE RIGHT TO LIFE
}

\section{Pedro Paulo Almeida Martins ${ }^{1}$}

Marla Anaiê Belfort do Nascimento ${ }^{2}$

RESUMO: A violência de gênero com a mulher é um conflito e ocasiona um grande problema social, pois se trata de um fenômeno múltiplo e complexo, cujo problema em questão tem destacado importantes, debates, seminários e discussões teórico-filosóficas e, no intuito de abordar também essa questão numa visão sobre questionamentos éticopolíticos. O presente artigo se mostra capaz em poder articular uma melhor perspectiva para o gênero afetado, neste caso será um processo de análises sobre violência em suas dimensões subjetiva, histórica, social e cultural; buscando assim uma melhor leitura crítica acerca das definições desses conflitos. Ao ter olhar sobre a problemática em questão, percebe-se sim a presença de uma cultura machista e patriarcal brasileira, ainda muito enraizada e com alguns valores e procedimentos de outras gerações, revelando uma postura de legitimação e banalização contra todas as legislações recentes, como exemplo a Lei Maria da Penha, buscando assim uma tentativa de coibir e talvez tratar de forma respeitosa e segura o direito à vida para a mulher. Este artigo visa evidenciar e também numa mesma linha de pensamento, enaltecer a presença da mulher como ser humano, buscando desta forma empreender mudanças legais e sim poder aplicá-las, políticas públicas com efetividade e tratamento cultural na afirmação dos direitos humanos das mulheres. Por fim o propósito maior desta fala escrita é promover tais perspectivas, propondo uma melhor expectativa em entender sim tais problemáticas contra a violência com as mulheres, e tendo a permissividade em articular uma compreensão com a perspectiva ética e histórica dos

\footnotetext{
I Bibliotecário, tecnólogo em Gestão pública, 4 titulações de pós-graduações, i MBA, graduando em Ciências Sociais e Direito. Lattes: http://lattes.cnpq.br/3951670487194507 Orcid: https://orcid.org/oooo-ooo2-349o8784. Faculdade Católica de Rondônia- Porto Velho, Brasil. E-mail: pedropaulogestorpublico@gmail.com.

${ }^{2}$ Graduanda em Ciência Sociais. Orcid: https://orcid.org/oooo-ooor-7887-024X Universidade Federal de Rondônia - UNIR, Porto Velho, Brasil. E-mail: marlaanaie@gmail.com.
} 
direitos humanos, tornando possível incorporar-se assim das dimensões ética e política ao olhar crítico e complexo sobre a violência contra a mulher.

Palavras-chaves: Gênero. Social. Mulher. Ser Humano. Violência.

ABSTRACT: Gender-based violence with women is a conflict and causes a major social problem, as it is a multiple and complex phenomenon, whose problem has highlighted important theoretical, philosophical debates, seminars and discussions and, in order to to also address this issue in a view of ethical-political questions. The present article is able to articulate a better perspective for the affected gender, in this case it will be a process of analysis on violence in its subjective, historical, social and cultural dimensions; thus seeking a better critical reading about the definitions of these conflicts. When looking at the issue in question, one can perceive the presence of a macho and patriarchal Brazilian culture, still very rooted and with some values and procedures from other generations, revealing a position of legitimation and trivialization against all recent legislation, such as example the Maria da Penha Law, thus seeking an attempt to restrain and perhaps treat the right to life for women in a respectful and secure manner. This article aims to highlight and also, in the same line of thought, to praise the presence of women as human beings, thus seeking to undertake legal changes, but to be able to apply them, public policies with effectiveness and cultural treatment in the affirmation of the human rights of women. Finally, the main purpose of this written speech is to promote such perspectives, proposing a better expectation to understand such problems against violence against women, and having the permissiveness to articulate an understanding with the ethical and historical perspective of human rights, making it possible to incorporate in this way, from the ethical and political dimensions to the critical and complex look at violence against women.

Keywords: Gender. Social. Woman. Human Being. Violence.

\section{Entendendo a problematização com a violência contra a mulher.}

O processo de formação e estruturação para o combate e, tentativa em poder combater de forma eminente ao problema contra a violência de gênero contra a mulher, se faz necessário entender num primeiro momento todo um processo de violência de gênero se expressando assim como se reproduzindo por questões culturais, sociais, e em muitos momentos por meio de comportamentos decorrentes que foram em algum momento apreendidos por uma sociedade historicamente e socialmente violenta, machista e em muitos momentos virem a considerar um erro ou falha por parte da mulher em querer questionar, argumentar, ou se quer pensar e ter uma opinião em meio às instituições como 
igreja, escola, família e Estado, que contribuem diretamente e dão força para a opressão masculina sobre a feminina.

A violência de gênero está sim, presente na cultura de todos os países, ainda que independentemente do seu grau de desenvolvimento, é possível verificar bem como registrar seja em maior ou menor escala. Quando o assunto é falar de questões culturalmente, esta temática provoca conflitos e até mesmo divisão de opiniões por um questão historicamente e vem desta forma podendo afirmar que a mulher vem sendo socialmente oprimida de acordo com valores específicos de uma determinada época, ou seja, provoca uma confirmação sobre quem provoca tal violência são diretamente influenciados pelas principais instituições sociais que em muitos momentos da história do mundo apresentam a figura da mulher sendo totalmente prejudicada e em muitos destes episódios tendo suas vidas ceifadas por um erro, cujo estes contribuíram e ainda contribuem para disseminar uma ideia deturpada de que esta é um ser inferior, frágil e com instintos de proteção apenas.

Diante da era da sociedade da informação, no mundo globalizado, temos maior acesso à informação pelas tecnologias de comunicação, o que leva informação em tempo real, integral e instantâneo a esta civilização. A sociedade está enfrentando o maior problema social de todos os tempos, a violência doméstica, aprender a conviver sem acirramentos dos polos binários, entre mulher e homem no mesmo espaço, em casa, entretanto o índice da violência contra as mulheres subiu, os números vêm aumentando, diante da pandemia global.

A grande questão a ser discutida e compreendida, a fim de discutir nesse primeiro momento uma problematização para tantos os desafios em viver em quatro paredes, onde há um lugar seguro, ou até mesmo um local que haja proteção, incorrem nos desafios dos infratores que vem atualmente causando sérias consequências à sociedade. 


\section{Iniciando um processo evolucionário diante dos conflitos contra a mulher.}

Para podermos iniciar um processo de estruturação diante do convívio social, é necessário primeiramente incluir questões de diálogo, companheirismo, reciprocidade, processo de convivência; elementos que na ausência ou falha em aplicabilidade de alguns destes pontos, inicia um grande conflito, cujo a relação é vista como um problema, contudo, estes são os problemas sociais que causam sim um total desajuste ou disfunção na sociedade.

Esta falta de desarmonia na sociedade, acabam acarretando discussões, desentendimentos, bem como os delitos, as infrações às leis, uma quebra das normas sociais entre as partes envolvidas, provocando em muitos casos a retirada da liberdade e por fim o fim da vida para a mulher.

A grande questão sobre a problemática atual em uma sociedade que instiga atos com a violência de gênero contra a mulher, tem tido tomada de força com apoiadores que incentivam a agressão e perpetuação da agressão contra a mulher. Ese conflito pode ser observado por muitos que de fato vai de encontro a violência ao sexo feminino, alimentando assim nos dias de hoje, mesmo que o Brasil tenha avançado na reformulação da legislação da Maria da Penha.

Uma forte aliada ao combate e tratativas é uma legislação ainda bem recente que está também em vigor ,neste caso trata-se da atual lei do feminicídio 13.104/I5 punindo com rigor os criminosos que matam mulheres por questões relacionadas à violência doméstica.

A discriminação pelo fato deste ser humano ser do sexo feminino de nada irá adiantar se o discurso ainda inconsequente e desmoralizado continuar alimentando sim a violência de forma brutal, desrespeitosa e totalmente covarde.

O ponto central a ser entendido e aplicado ao longo do trabalho, é desenvolver sim que deve-se trabalhar desde a educação de base, ou seja, a educação básica com crianças desde o primeiro momento com um convívio em sociedade. 
Uma criança que tenha sim uma estruturação e que seja educada com princípios e aplicabilidade da ética e moral, respeitando sim seu colega de ambiente escolar, ou até mesmo no próprio ambiente familiar que deve e sim é necessário trabalhar o diálogo e respeito e deste modo sabendo dos direitos e deveres, consequentemente vai ter ações canalizadas e assertivas para o futuro.

\section{Compreendendo gênero e sua relação com a violência com a mulher.}

O conceito de gênero foi estudado e desta forma proposto como termo aceito e estudado até os dias de hoje, por estudiosas feministas americanas Stoller e Gayle Rubin, na década de 70 ,tendo como um objeto de estudo dos feminismos, tratando assim com uma linha de estudo que tem como conceituação a proposta para superar e/ou desmistificar o que até então tratava o correto ou único como o que apontar e julgar sobre o determinismo biológico, cujo a relação ao uso do termo apenas tratava sobre a sexualidade ou diferenciação sexual e destacar a construção social das identidades de homens e mulheres.

Segundo Machado (1998), é importante destacar o princípio dos estudos em poder ressaltar sobre o processo de análise de gênero, aonde vem com uma nova visão a qual instaurou um novo paradigma metodológico, ou seja, toma como ponto de partida tomando propriedade de três pilares fundamentais. O primeiro ponto a ser esclarecido, é quanto a ruptura com o essencialismo biológico, no qual torna um processo de quebra de tabu e mostra que sim a mulher é mais que um ser de fragilidade ou até mesmo apenas aquele indivíduo que não tem a capacidade de atuar em um tipo de profissão ou ocupar um cargo ou se quer poder ter lugar de fala ou posicionamento diante da sociedade.

Num segundo momento, Machado afirma quanto a retratação sobre o privilégio metodológico no que diz respeito às relações de gênero, sendo estas postas em contraposição às categorias que já foram impostas a uma sociedade onde coloca o homem superior a mulher; onde neste momento é possível observar e entender por uma ótica mais crítica.

A necessidade de provocar essa disruptiva tão enérgica com os processos sociais, é provocar uma linha de pensamento é necessário ajustar aos novos tempos com legislação 
aplicável e com a tentativa em poder conter o desenfreado descontrole de tentativas e em muitos casos a consumação do ato de feminicídio contra a vida.

Por fim é necessário e totalmente afirmativo quanto a importância da transversalidade de gênero nas demais áreas do social. Isso demonstra o quanto é importante para uma sociedade com acesso à informação, tecnologia na palma das mãos e, possibilidade e acesso ao conhecimento podendo assim ser compreendido como uma categoria de análise com estatuto teórico e epistêmico e caráter estruturante da sociedade

\section{I Retificando o pensamento do poder do homem sobre a mulher na sociedade}

A percepção de violência para os homens nesse momento está ligada diretamente com um processo que está associado com uma identificação do excesso da ação por este indivíduo, ou seja, ele sente a necessidade, vontade, desejo, bem como outros sentimentos que este mesmo homem provoca e acaba ultrapassando os limites, estes que foram estabelecidos pelo social, cultural, histórico e/ou subjetivo.

Com isso inicia um processo de violência com a mulher, onde neste caso são os mais diversos vistos pela sociedade e exemplificados de formas acidentais e até fatais em muitos casos.

Fundamentar-se de uma necessidade de poder, e neste caso o homem que provoca esta violência e acarreta a sua manifestação com um excesso de poder, machismo, fala superior a mulher, e outros fatos que provocam alteridade.

O fato é quanto ao estudo de compreender e sim, poder desconstruir tais inadequações bem como a não aceitação de seu desejo imposto à mulher e, provocando assim uma violência que em muitos casos acarreta em situações fatídicas.

Segundo um ponto de intersecção com a construção teórica, para Chauí (2003), é necessário que seja demonstrado a oposição de conceitos como violência e ética:

A violência se opõe à ética porque trata seres racionais e sensíveis, dotados de linguagem e de liberdade como se fossem coisas, isto é, irracionais, insensíveis, 
mudos, inertes ou passivos. $\mathrm{Na}$ medida em que a ética é inseparável da figura do sujeito racional, voluntário, livre e responsável, tratá-lo como se fosse desprovido de razão, vontade, liberdade e responsabilidade é tratá-lo não como humano, e sim como coisa. (p. 42)

Ao iniciar um processo de formar opinião, tornar um assunto comentado e discutir de forma relevante, faz com que a interpretação e julgamento observa-se ao ler os noticiários, um sentimento triste e totalmente infeliz pelas frustradas tentativas de investidas da própria justiça ao indivíduo que comete o crime contra a vida para com as mulheres, isto é, atitude pela qual provoca um rompimento e bloqueio por parte do homem que comete tal delito.

\subsection{A aplicação da relação de convívio ético e com respeito a vida dentro da sociedade.}

Em primeiro lugar, Durkheim explica através dos seus estudos o que é fato social, vale destacar que é a maneira de agir, pensar e de sentir do coletivo para o ser, que logo determina a força que exercem sobre os indivíduos, desde que ocorra no coletivo e respeite as normas de coercitividade, generalidade e exterioridade.

Isto traz recordações e perceptividade de um pouco do funcionalismo estrutural de Durkheim, no caso a coercitividade, que diante do fato social, obriga de certa forma, a forçar, a enfrentar e lidar com o sistema opressor, tendo esta diferença do binarismo entre o dominador e dominado, porém todos nós sabemos que a mulher enfrenta essa disputa, certamente o feminicídio.

Vale destacar que, para:

(DURKHEIN, 1983, p.4,) Entretanto, como os exemplos que acabamos de citar (regras jurídicas, morais, dogmas religiosos, sistemas financeiros, etc.) consistem todos em crenças e em práticas constituídas, poder-se-ia supor, com base no que precede, que só há fato social onde há organização definida. Mas existem outros fatos que, sem apresentar essas formas cristalizadas, têm a mesma objetividade e a mesma ascendência sobre o indivíduo. É o que chamamos de correntes sociais. Assim numa assembleia, os grandes movimentos de entusiasmo ou devoção que se produzem não têm por lugar de origem nenhuma consciência particular. 
Trabalhar estes padrões existentes; padrões estes considerados externos a que estarão sempre existentes independente da nossa existência, por exemplo, a interação social no coletivo é obrigatória desde que obedeça às regras da sociedade, o que as pessoas pensam, sentem ou fazem independente de suas vontades individuais, o comportamento é estabelecido pela sociedade, não dá margem a escolhas.

Podemos entender que o texto, em estudo, vai de encontro com o fato social, pois demonstra pontos cruciais de modo de agir autoritário com base numa ideologia de governo que é austera, algo totalmente escroto que fere as normas de coercitividade e generalidade, mas infelizmente existe no momento, bem como discursos fora da diplomacia que traz consequência na política externa.

Trabalhar todo esse assunto tem por necessidade atentar-se aos padrões externos que sempre existirão independente da nossa existência, por exemplo, a interação social no coletivo é obrigatória desde que obedeça às regras da sociedade, o que as pessoas pensam, sentem ou fazem independente de suas vontades individuais, o comportamento é estabelecido pela sociedade, não dá margem a escolhas.

\section{CONSIDERAÇÕES FINAIS}

O grande conflito a ser tratado, é com relação à gravidade das situações de violência com a mulher, nesse contexto envolve todo um problema com conflitos de gênero quanta sociedade e, tem por esta exigido cada vez mais estudos e reflexões teórico-práticas, no que dizem respeito que embasam a compreensão deste complexo fenômeno.

No presente trabalho, foi possível construir uma dimensão possível para melhorar o processo de compreensão sob uma ótica com um olhar de criticidade e, uma melhor compreensão dos sentidos éticos bem como os significados da violência com a mulher.

Entendemos que a articulação da dimensão de gênero com uma visão mais aprofundada do fenômeno da violência nos permite compreender como esta é marcada na ainda por muitos fatos com subjetividade e no encontro com a alteridade, a partir de uma demarcação de poder, de negação e de opressão às mulheres. 
Tais compreensões possibilitam uma melhor reflexão acerca das definições e tipificações da violência contra a mulher, enfatizadas pela Lei Maria da Penha, identificando a relevância dessa conceituação clara diante da questão do gênero e conflitando desta forma todo o processo social, podendo assim afirmar a amplitude e a diversidade pelas quais tal violência pode se expressar.

Assim, é muito importante o conhecimento a respeito dessas tipificações para subsidiar a compreensão sobre o fenômeno da violência de gênero contra mulheres e orientar a atuação técnica que se proponha ao enfrentamento e à superação de tal violência.

Entendemos, porém, que essas definições legais apresentam suas limitações, principalmente no que concerne a abranger toda a complexidade e subjetividade envolvidas na vivência da conjugalidade, da violência e das relações de gênero.

Deste modo é visto um ato de releitura de tais definições a partir de uma ampliação do olhar para a perspectiva dos direitos humanos de forma a nos apropriarmos da dimensão da negação da dignidade humana que permeia toda a violação de direitos e se configura enquanto violência.

Além do mais, se faz importante sim toda uma perspectiva que seja, trago à tona a necessidade real de uma reflexão sócio-política e ética diante de uma compreensão crítica e complexa da sociedade, da história, das leis e costumes, dos direitos e violações e das próprias noções de humanidade e dignidade.

Nos dias atuais, sabemos que não há que se falar em verdades absolutas. Com isso os possíveis agressores, não tendo assim um padrão de comportamento considerado universal, ou seja, em conflito com a relação ao gênero, à sexualidade propriamente dita, tendo desta forma um processo como o mais correto, o normal, provocando assim da mesma forma, não há que se falar em hierarquia não existindo tais diferenciações.

Somos todos iguais, em abstrato, quer dizer então que temos tais complexidades, porém é necessário sim haver especificidades para cada ser humano, sendo uma característica fundamental do ser humano. Isso não seria diferente para a mulher, cujo isto 
implica uma série de relações de inter-relações: sociais, econômicas, políticas e inclusive simbólicas.

Além disso, todos são seres processuais, o que significa que, desde o nascimento até o fim da vida, constantemente muda-se conforme o espaço e tempo entre outros, mostrando assim procedimentos executáveis e situações que podem sim adaptar-se ou modificar quanto ao comportamento e hábitos ou costumes que tenham heranças culturais, crenças e, principalmente circunstâncias que tornam o feminicídio de forma atenuante, e na verdade o processo deve ser contrário a fim de termos melhores relacionamentos, convivências, sociabilidade entre todos , podendo desta forma evitar ou até mesmo coibir de forma intensa para escapar desse sistema opressor, sendo assim necessário que se rompa com o universal e se adote uma visão emancipadora.

\section{REFERÊNCIAS BIBLIOGRÁFICAS}

BRASIL. Lei Maria da Penha. Lei n. II.340/2006. Coíbe a violência doméstica e familiar contra a mulher. Presidência da República, 2006. Disponível em: https://www2.senado.leg.br/bdsf/bitstream/handle/id/496319/o00925795.pdf . Acesso em 25 abr 2021.

BRASIL. LEI № 13.104, DE $9 \quad \mathrm{DE}$ MARÇO $\mathrm{DE}{ }^{2015 .}$ http://www.planalto.gov.br/ccivil_03/_ato2015-2018/2015/lei/li3104.htm. Acesso em $24 \mathrm{abr}$ 2021

DURKHEIM, Émile. As Regras do Método Sociológico. São Paulo, Ed. Abril Cultural, 1983, IoIp

MACHADO, L. Z. (1998). Gênero: um novo paradigma? Cadernos Pagu, II, IO7-I25. 